Om Aftenen og Dagen efter var de fleste sammen med deres Varter med Familie. Vi takkede for den os viste store Grestfrihed i enhver Henseende, og om Formiddagen den 12. forlod de fleste Kubenhavn for at naa hjem til deres Hjemstavn.

Ankommen i mit Hjem blev der afholdt en lille Festlighed for de narmeste Paarørende, og efter en lille Ferie maatte der tages fat igen for at danne den Eksistens, som cr ngdvendig til Livets Ophold.

En Henvendelse fra min Side til Direktør Hübbo i llaclerslev Bank resulterede i, at jeg, saasnart jeg onskede det, kunde tiltræde min gamle Plads og tage Del i det Aibejıle, jeg havde faaet saa kært.

Endnu i flere Aar efter clenne veloverstaaede Krigstid stod jeg i Forbindelse med Valkyriens Chef. Officerer og Besatning. Af Kacletkorpset fik alle d a n s ke Sonderjyder, der var ned paa Rejsen et stort Fotografi af Valkyrien, der var forsynet med enhver Moltagers Navn, Fange Nr. o. s. v., og jeg siger a 1 le cler har hjulpet med til denne vor hurtige Hjemscudelse, hvis sidste Del, Togtet med Valkyrien, blev gennemfort saa smukt, den danske Marine til Ere, min hjerteligste Tak!

\title{
I rumænsk Fangenskab.
}

Af Jakob Petersen, Mjolden.

Den 1. November 1915 blev jeg indkaldt som Soldat, jeg var dengang 42 Aar gammel. Jeg kom til at ligge i Slesvig, hvor vi skulde uddannes, ingen af os havde før varet Soldat. Tjenesten var streng, syntes vi, og vi klagede os til hverandre. Vor In- 
derofficer sagde nok, at vi maatte være glade, saalænge vi kunde holde os her. Det viste sig siden, at han havde Ret. Allerede siilst i November blev alle Nordslesvigerne udtaget til en Transport til Rusland. Det blev sagt, at vi var farlige at holde herhjemme i Provinsen, bedst at vi kom til Fronten. Vi var dog ikke Danskere nok, Resten bestod saa af straffede Personer, og vi kom ikke afsted før den 28. 12. I Julen havde de fleste af os Besøg af vore kære hjemmefra, vi vidste, at Afskeden snart vilde komme, og maaske saas vi ikke mere.

Den 13. Januar kom vi til Lida i Rusland, efter flere Dages Ophold i Kønigsberg. Vi laa paa Kasernen og skulde uddannes videre. Allerede den 9. 2. var vi i Skyttegraven ude ved Beresinafloden, der hvor Napoleon maatte vende om for 100 Aar siden. Ln Kammerat fra Haderslevegnen og jeg var de eneste Danskere ved 1. Komp. i Landv. Inf. Reg. Nr. 5. Det var med en underlig Følelse og alvorlige Tanker, at vi i Udkanten af en Skov dukkede ned i Skyttegraven. Vi traf det dog forholdsvis heldig. Vi blev snart aflost i Skyttegraven og kom i Reserve. En Tid flakkede vi rundt forskellige Steder i Rusland til i September, da fik jeg Orlov i 14 Dage. Det var dejligt at være hjemme; men Afakeden var enthu værre end forste Gang, da vi nu vidste, hvad vi gik ind til. Det tog 8 Dage at finde vore Kammerater, som i Mellemtiden var kommet til Galizien, og, netop da vi kom, blev aflost i en skrækkelig Stilling; de var saa udmattede og forfærdeligt snavsede, saa vi næsten ikke kunde kende dem. Vi var nu i forskellige Stillinger. Ved Stochod laa vi en kort Tid saa nær paa Russerne, (paa Natposten kun i $40 \mathrm{~m}$ Afstand), at vi kunde samtale med dem, det vil sige, 
hvem der talte Polsk. Straks da vi kom i Stillingen, sagde de, at naar vi vilde lade være at skyde, saa gjorde de det heller ikke, og vi holdt Ord paa begge Sider. Artilleriet skød dog stadig over os, saa Køkkenet ikke kunde komme ud til os, vi maatte hente Maden temmelig langt borte ved Nattetid. Der var flere paa begge Sider, som gik over og byttede Fodevarer, Russerne kunde give meget Brod og sukker for en Snaps Rum. Den 3. 12. kom vi i Toget, og det blev en længere Rejse, i 4 Dage og 3 Natter rejste vi over Lemberg gennem Ungarn og Siebenbürgen, kom ud af Toget i Kronstadt (Brasno), hvor vi opholdt os et Døgn, saa gik det videre tilfols, og Dagen før Juleaften gik vi over den rumænske Grænse; ved et lille Hvil (ler hørte vi de første Kugler suse over os. Juledagene var meget triste, især manglede vi Levneismidler, anden Juledag maatte vi tilbage efter Fødevarer, og maatte da i over et Døgn skiftevis bære en saaret Kammerat med til en Forbindingsplads. I en Jernbanetunnel, hvor et Tog laa sprængt, traf jeg en Landsmand, han var kommen bort fra sit Kompagni og flakkede ene rundt i flere Dage. Vi onskede hinanden et godt Nytaar og paa Gensyn hjemme. Vi træfes jæunlig og taler da om Mødet $i$ Putnaclalen. Vi var nu i Bjerg- og Skovegne, og vi gik kun langsomt fremad, idet vi drev med Fjenden, som af og til gjorde Molstand. Den 13. Januar 1917 satte Fjenden sig fast. Kompagniet havde da haft nogle døde og saarede, nogle Forposter kom i Fangenskab, (om de gik eller blev taget, ved jeg ikke). Vi fik nu travlt med Skandsearbejde og med at bygge "Unterstände«. Kompagniet kom til at ligge i en By Marastir, og nogle af Beboerne blev hos os de første Dage, men da Rumænerne begyndte at bombardere 
Byen, maatte de væk; de blev dog i lang Tid ved at komme, især om Natten, for at hente af deres Ejendele. Tilsidst fik Vagten Ordre paa at skyde dem, ja der blev endog lovet 14 Dages Orlov til den, der skad en inden for Byens Granser. De var næsten ikke til at formaa til at blive borte mell det gode. Vi var mange, der havde ondt af det for dem, og jeg tror ikke, der blev nogen skudt af vort Kompagni.

Her blev vi nu til den 24. Juli, saa kom Befrielsesdagen i Form af Fangenskab, at det skulde blive endnu værre, anede vi ikke dengang. Den 22. Juli, en Søndag Formiddag, begyndte Fjenden at bombardere vor Stilling i lang Udstrakning med "Trommeild «, som varede i to Dogn, da var alt javnet med Jorden.

Jeg var med paa den silste Post forude paa en Høj eller et lille Bjerg, hvor vi havile gravet os ned $i$ Læsiden, fra Udkigshullerne havde vi en fortræffelig Lidsigt. Da det begyndte at dages den 24. kunde vi se Rumænerne komme i vildt Løb nogle $100 \mathrm{~m}$. Nord for os, og min Kammerat udbrød da, "Se, de kommer som Lover". Vi fik nu Ordre til at gaa $i$ Skyttegravene, men det varede kun kort Tid, for der var kommen en temmelig stor Styrke igennem ned $i$ Nærheden af os, og da vi saa, at de paa en aaben Plads gav sig til at sætte Maskingeværerne i Stand. gik vi i Løbegravene og løb tilbage til neste By (Gogøi). Vi havde kastet vore Tornystre for at løbe hurtigere. Flyverne kredsede hele Tiden over os. Vi samlede os nu i "Kaiser Wilhelms Schlucht", en Kløft mellem Fjeldene. Indtil Gennembrudet var det kun Artilleriet, der besørgede skydningen, men fra Daggry til hen paa Eftermiddagen var alt i Gang, det var en saa øredøvende Larm, som kun den 
kan tronke sig, der har oplevet det. Vejen frem eller tilbage var spærret for os. Der var en Mulighed endnu at komme bort paa, nemlig til siden over en Dal, hvori der løb en Biflod til Putna. Der var en Del Buskads ved Siderne, men i Midten paa begge Sider af Floden var der flad Eng, Rumpenerne havde en god Udsigt fra deres Stilling, og beskad da ogsaa Strakningen med Schrapneller. Jeg var sammen med 2 Mand paa Vej over Dalen, men fortrod det og gik tilbage. Officerer saa vi ikke noget til, de havde i god Tid trukket sig tilbage, vor Kompagniforer blev dog saaret og maatte bæres bort. Reserven, som vi haabede paa, mærkede vi ikke noget til. Vi raadslog nu, hvad vi skulde gøre, og kom til det Resultat, at vi vilde lade os tage til Fange.

Vore Vaaben kastede vi sammen i en Hob og satte et lille hvid Flag ud paa en stang som Tegn til Overgivelse.

Vi var nu ca. 80 Mand samlede, vi kunde intet se undtagen Flyverne, men vi kunde hore, at Fjenden eller Befrieren var os nær.

I min Dagbog har jeg skrevet: "Endelig kom det ventede Øjeblik, som blev helt højtideligt.«

I spidsen for ca. 30-40 Mand med opplantet Bajonet kom en ung statelig skikkelse. Han befalede paa Tysk, at vi skulde rakke Hænderne $i$ Vejret, og Mandskabet omringede os.

Han holdt nu falgende Tale til os ligeledes paa Tysk:

"Soldater, I er nu fangne, og vi skal ingen Fortræl gore Eder. I har kæmpet for Eders Fædreland, ligesom vi har kæmpet for vort. Lad os nu sammen knale og becle den kære Gud, at denne skrækkelige Krig snart maa ophøre." Han befalede sine Mænd at vare rolig, og vi knælede alle. 
Vi maatte saa afgive vore Lommeknive, Breve og andre Papirer, især Landkort. Han spurgte os saa, on vi havde faaet Brod for i Dag. "Jeg kan intet give Jer, men i Morgen skal I faa."

Vi blev nu forte tilbage gemmem vor sonderskudte Stilling, hvor der laa flere dode og saarede, jeg mindes saa tydeligt en, der laa og ravede rundt paa Jorden, han havde. faaet en Kugle gennem Hovedet, ng sagde, da vi gik forbi: Kammerater Kammerater! Der var ogsaa flere saareile iblandt os, en maatte vi bare i to Dage. Naste Dag fik vi saa Brød, men heller ikke andet. Bevogtningen var nu fransk Kavalleri med dragen Sabel, som de stodte til os med, naar ller kom en lidt uden for Rakkerne. Naar vi moilte karende Militær, slog de os med Piskell. Mine Tanker var nu meget hjemme los mine krre, jeg viılste jo, at cler vilde gaa Uger, ja maaske Maaneder i Uvidenhed paa begge Sider. Jeg tienkte dog ikke at det skulde var 9 Maaneder.

1 \& Dage gik vi til Fods, for vi kom til Fangelejren i Bacatinni, de to Natter laa vi ude under aaben Himmel uden Kappe eller Tapper, dem tog the fra os. Fangelejren bestod af en Mangde TraBarakker med Trægulv, hvorpaa vi laa om Natten uden Halm eller noget. Om Dagen skulde vi opholde os ude i frisk Luft, der blev fortalt, at de, der havde boet der før os, næsten var døde allesammen af Tyfus, om det passer, ved jeg ikke, men i Nærheden kunde vi se en Indhegning med en Mængde Trækors, vi maatte ikke komme derhen.

Kosten bestod af Brod og The, om Middagen Majsgrød med lidt Olie og, naar man var hellig, en lille Flæsketærning. Grøden smagte os ikke, skønt vi ikke var forvænnede fra Skyttegraven. Foran- 
rringen af Kosten og en skrakkelig Varme gjorde, at vi blev mange syge til at begynde med. Lægenuiller hjalp ikke, det maatte vi vænne os til.

Der kom stadig flere Transporter af Fanger, og jeg spejclede efter, om der ikke skulde komme en Landsmand, men der kom ingen, saa jeg i de 9 Maaneders Fangenskab ikke talte mit kære Modersmaal. Vi kom straks alle i Forhor og maatte opgive vore Adresser haade hjemme og i Felten, det var til Rode Kors. Efter nogle Dages Forløb blev Elsasserne skilt fra os og kom siden bort, hvorhen, ved jeg ikke. Jeg gik da igen til Kontoret, og provede paa at gøre dem forklarligt, at jeg ikke var Tysker, men forgaves. En af de forste Dage fik vi udleveret et Kort, hvorpaa vi matte skrive hjem, men kun paa Tysk eller Fransk. Dette Kort tik min Kone i Februar samtidig med Meddelelsen fra Rode Kors, at jeg var kommen i Fangenskab. Siden fik vi Lov at skrive to Gange, det ene Kort kom forst, efter at jeg var kommet hjem.

I Oktober fik jeg ad Omveje en rumænsk Feldwebel til at besørge et Brev til en Svoger i Danmark, som han modtog i Februar, og sendte straks min Kone et Telegram. Grunden til, at Posten tog saa lang Till eller helt udeblev, var, at len skulde over Rusland, og enhver ved hvilke Tilstande der var. Efter godt et Par L'gers Ophold i Fangelejren kom vi ud paa Arbejile, blev læssede i Jernbanerogne, og Rejsen tog to Nætter og en Dag. Vi kom fi3 Fanger og 5 Vogtere i en Kreaturvogn, fik sjælden Lov til at komme ud, og ikke altid, naar vi havde det behov, saa vi forlod med Glæde Vognen, da vị var ved Maalet.

Naar vi skulde skifte Arbejdsplads, hvad enten 
det var tilfods eller med Toget, fik vi gerne Levnedsmidler udleveret til fire Dage, det bestod da af et Brod til hver Dag, to meget saltede smaa Fisk, to Haandfulde Ost og noget Salt. Osten bestod af tyk sur Mælk, som Vallen var presset fra. Fiskene var saa salte, saa vi næsten ikke turde spise dem for Torsten bagefter, da det ofte kneb med at faa Drikkevand. Vaske os tænkte vi slet ikke paa. Arbejdet. bestod af at grave skyttegrave, Reservestillinger 0.1. I Førstningen kunde vi nok overkomme det Stykke, vi fik afsat, siden kneb det, da Brødet blev mindre, og vi mere udmattedes. Ofte maatte vi gaa mange Kilometer til Arbejdspladsen. En Dag havde vi været særlig langt ude. Om Aftenen, da vi gik hjem, faldt to Mand om af Udmattelse og maatte køres hjem til Barakken; da var de allerede bevidstlose. Vi gjorde, hvad vi kunde, for at faa dem opvarmet, men intet hjalp. Den ene døde næste Dag og Natten derefter den anden uden at vare kommen til Bevidsthed. En anden Dag, mens vi gik til Arbejle, kom vi forbi en Kirke. Ude paa Kirkegaarden stod en Forsamling af Mennesker, og vi horte flere Skul. rangevogterne lod os forstaa, at det var Fanger, som havde gjort Opstand, og nu blev skudt paa Kanten af deres Grav, de selv havde kastet. I de forste Maaneder, da det endnu var meget varmt, fik vi Lov til at bade, naar vi kom til en Flod eller et mindre Vandløb. Naar vi saa vaskede Skjorten straks, var den tør, naar vi opholdt os et Kvarters Tid i Vandet. Men ogsaa dette Gode fik en Ende, da Vinteren kom. Naar vi skiftede Kvarter, laa vi gerne de forste Nætter paa den bare Jord, indtil vi fik bygget en Barak. Denne blev bygget paa følgende Maade: Fra den nærmeste Skov hentede vi Træ, 
satte Spær imod hinanden ligesom Rejsningen af et Hus herhjemme, men ikke højere, end at en Mand godt kunde gaa lige op i Midten. Den var ca. seks Alen bred, saa vi laa i to Rækker, omtrent Hundrede Mand i hver. Saa blev der slaaet Lægter paa, lagt Grene og Græs mellem Lægterne og et Lag Jord venpaa. $V i$ var kisteglade, naar vi kunde rykke ind $i$ vort nye Hus. Vi samlede saa noget Græs til Lejet og sov udmærket, naar vi kunde faa Ro for de Graa, der var mange. I Vintertiden gravede vi os lidt ned i Jorden, der var der lunere, og undertiden fyrede vi paa følgende Maade: Vi tændte et Baal, midt i Huset, men alle Mand maatte rykke ud, til det var udbrændt, da det næsten altid, var grønt Træ fra Skoven eller Arbejdspladserne, vi fyrede med. Saa længe Gløderne holdt sig, kunde der være helt lunt. Døren var ogsaa af Grene og Græs. En Dag, vi kom hjem fra Arbejde, var der brændt en af Barakkerne, det var et stort Tab, da ingen havde forsikret. En Dag kom en tysk Flyver og kredsede over os nogle Gange, den prøvede paa at lande, men fik ingen Forbindelse med os. Saa gik den løs paa en Lænkeballon, som var tøjret i Nærheden, og skød den i Brand. Da Tyskerne saa det, jublede de og sprang højt. Derfor blev vi straffede allesammen med, at vi i fjorten Dage fik mindre Brød, det var slemt nok, da vi fik for lidt i Forvejen. Kosten blev stadig ringere og Portionerne mindre. Det hændte af og til, at der deserterede et Par Mand, nogle af dem hørte vi intet om, andre blev fangede igen, saaledes to Mand fra andet Kompagni. De blev ført rundt fra det ene Kompagni til - det andet og pisket, mens vi stod i en Kreds om dem og skulde se til. Da raabte en højt: "Lad os vende os om, og ikke se 
paa det«. Det skulde han ikke have gjort, for det gav igen Anledning til mintre Brøul.

Et stort Gode var det for os i Efteraarstiden, at vi tit kom gennem Kartoffelmarker, hvor vi saa fyldte vore Lommer. Naar der saa var Lejlighed, flk vi Ild paa og stegte dem, eller kogte dem, naar vi kunde faa Vand. Fangevogterne havde ikke noget imod det. da de selv gjorle det samme, naar der ingen Officerer var i Narheden. Den 9. 11. brød et forfirdeligt Uvejr los over os med Torden og Regn. Vi var da ude mellem Bjergene, og ligesom det var dreven over, kom let tilbage igen. Det var, som stulte det mod Bjergkanten. Saadian blev det ved nange Gange, imens Regnen strømmede ned, saa jeg har aldrig set noget lignende. Vi var snart gennemblolte, og naatte holde op med Arbejdet, da Gravene hurtigt fyldtes med Vand. Dette var eneste Gang, vi lod os forhindre ved Arbejdet. Kun Halvlelen af os havde den Gang faaet Kappe udleveret til Vinteren, jeg var blandt de uheldige og gruede for Natten i den vaade Dragt. Det gik dog nogenlunde, da vi fik et Baal tandt midt i stuen, som den Gang var en Faarestald. Naste Dag var det det dejligste Vejr, saa blev vi torre igen. Et Held for os var det, at Vinteren var meget mild, kun sjalden Regn, ingen Sine og ikke haard Frost. Det var helt modsat Vinteren forud, da vi laa i skyttegravene - ogsaa $i$ Rumanien - da havde vi megen Sne, og Frosten var saa haard, at Piben fros i Munden paa os, naar vi stod paa Vagt. Forplejningen blev stadig daarligere. Meget lidt Brød, Maisgrøilen blev til Vælling og tilsidst mest Vand. En Dag gav de os hele Majs kogt i Vand, men det kuncle vi ikke spise, Majsen var og blev haard. En Dag om Ugen fik vi fersk 
Suppe. Kod var der ikke meget af, kun Hoved, Ben, Lunger og Nyrer. Naar man var særlig heldig, kuncle det give et stykke Lunge af Størrelse som en lilleTæudstik æske. Engang var der ogsaa Kartofler i, jeg fik to smaa, nænnede ikke at pille dem, det fyldte jo alt. Der blev nu mange syge, vi havde ikke meget at staa imod med. Nogle blev kort bort paa sygehus, og vi hørte ikke mere fra dem. Naar Sygdommen ikke var alt for haard, kom vi sammen og blev bragt ind til Byen. Ved en saadan Lejlighed fik vi baade os selv og vort Tøj vasket. Bagefter kom det $\mathrm{i}$ en Ovn og blev renset. Det tog flere Timer, i denne Tid gik vi nogen omkring og fros selvfølgelig. Bagefter var der stort Spektakel, da de, som kom forst, ikke havde fundet det rigtige Tøj. Dagene ind under Jul var meget triste. Humøret var langt nede. Tankerne var hjemme, Sulten var stor. En Dag fortaltes inde i Barakken, at der gik en Fangevogter udenfor Pigtraadshegnet med et Par smaa Brød, til ca. et halvt Pund Stykket, men han forlangte alt for meget for dem. Jeg gik straks ud og købte dem. Jeg græd af Glæde og syntes, at det var en dejlig Julegave. Da Kammeraterne fik det at vide, skændte de paa mig, fordi jeg havite givet alt for meget for dem. Dagen efter kom nogle Mænd tilbage, som havde været ude at hjælpe med Tærskningen. De havde faaet en Del Majskolber med sig, og jeg købte nogle af dem. Nu var Udsigterne bedre for Juledagene. Majsen lagde vi i Ilden, til den blev sort og skur, spiste den saa og fanclt dengang, at det var en dejlig Ret.

Saa kom Julen, og Tankerne gik hjem til de kære, hvor de samledes om Juletræ og gik til Kirke. Juleaften læste en, af Kammeraterne Juleevangeliet 
hojt, og vi sang "stille Nat, hellige Nat". Vi var ude for at se efter Fronten. Alt stille, men der blev skudt mange Lyskugler til Vejrs. Vel nok en Hilsen fra begge sider. Juledag havde vi fri for Arbejde. Vi havde Kirkegang. Det vil sige, vi blev stillet op udenfor Barakken, og Præsten talte til os, men ingen forstod det. Alligevel var der højtidelig Stemning. Bagefter talte Lægen, han kunde noget Tysk, om Julen og Hjemmet.

Arbejdet gik igen sin Gang, men jeg var saa plaget af (iigt, saa jeg næsten ikke kunde gaa. Kom igen sammen med nogle syge i en Trabarak, hvor der var Varme, saa det blev snart bedre. Fredsforhandlingerne maa nu have været i Gang og Lidsigterne til at blive enige gode, thi Arbejdet horte pludselig op. Vi gik en Tid i stor Spænding, men det hele endte med, at vi matte begynde at arbejıle paany. Dog var for mit Vedkommende Arbejdet forbi. Jeg fik en daarlig Haand af Overanstrengelse, og da der ikke blev gjort stort ved den, blev Resultatet, at Senerne tog Skade, og de tre Fingre paa venstre Haand trak sig helt sammen ind i Haanden.

Da Sulten stadig plagede os, begyndte vi at sælge de faa Genstande, vi havde faaet Lov at beholde. Pengepung, Ur og Forlovelsesringen. Jeg solgte mit Ur en Dag og skulde have $50 \mathrm{Lei}$, ca. fyrretyve Mark, et Par Brød og noget Majsmel for det. Dagen efter skulde Ombytningen finde Sted, men Vedkommende blev borte, og jeg har mit Ur endnu. Henimod Slutningen af Fangenskabet blev jeg budt en stor Sum Penge - 70 Lei - for min Forlovelsesring, men jeg modstod trods min sult.

I Februar kom en Kommisison fra de neutrale Lande for at undersige, hvordan vi havde det. De 
spurgte os ull og fik Sandheden at vide. Det hjælp. Vi fik nu storre Portion Mad, blev badet, fik Tøjet renset, blev klippet og barberet. Mad og Taj blev os tilsendt fra "Rale Kors«, begge Dele tiltrængtes haardt. Min Skjorte var dengang kun nogle Pjalter paa Overkroppen, det nederste var falden af.

Klæderne var meget brogede, le var skænket fra forskellige Lande. Fodtøjet var det ringeste. Vi fik kun Sandaler til at binde paa. Mine var saa store, at jeg kunde binde dem paa Støvlerne, hvor ler nesten ingen saaler var mere. Husker ogsaa nok, at Officererne, der tog imod os i Bukarest, pegrede paa dem og lo. For'st i Marts Maaned blev vi fri for Arbejulet igen. Der var sluttet Fred mellem Rusland, Rumænien og Tyskland. Havde vort Fangenskab varet ved til Krigens Ende, var sikkert ikke inange kommet hjem. - Vi afleverede mied stor (ilæcle vort Haandværkstøj, og faa Dage derefter tog vi Afsked med den Egn, hvor vi havde lidt saa meget. Den 1f. Marts kom vi tilbage til Fangelejren Bacatinni, hvorfra vi var gaaet ud. Der opholdt vi os i fjorten lange Dage, dog var vi inderlig glade, vi var jo paa Hjemvejen. Den 30. Marts sagde vi Farvel til Lejren i Bacatinni, kørte en Timestid med Toget, grik et Stykke Vej og kom saa til Frontlinjen, hvor vi blev godt modtagne af de tyske Soldater og fik nogle Cigarer. Kort efter kom vi til en Proviantlejr, hvor vi blev godt beværtede efter Datidens Forhold. Fik ogsaa udleveret et Kort og skrev et Par Ord hjem. Om Aftenen kom vi i Toget, og den 1. April Paaskelag om Eftermiddagen kørte vi ind paa Banegaarden i Bukarest til Tonerne af "Deutschland, Deutschland über alles«. En Del Militær og Røde Kors Søstre tog imod os. En General, vistnok Mackensen, holdt en 
kort Tale til os og lovede os Jernkorset. Jeg fik det log ikke. men føler det ikke som noget stort Savn.

Vi kom straks i Bad, og fik rent Tøj paa fra Top til Taa. Hvilken herlig Forandring. Med Biler blev vi kort gennem Bukarest ud til en lille Forstad, hvor vi laa i Karantæne i tre Uger. Her var vi lykkelige. Vi var pa Hjemvejen, var bleven rene, og fik atter god Mad efter at have sultet gennem mange Maneder. Jeg skrev straks hjem efter Penge, som kom i Lobet af en Uge, og nu kunde jeg købe forskelligt, Brod, Pibe, Tobak og mere. Samtidig med Pengene modtog jeg Brev hjemmefra, efter at jeg i ni Maaneder intet havde hort derfra. Det hjalp paa Humøret. Tiden blev os meget lang og ensformig, mens vi laa i Karantæne, kun et Par Gange var vi uden for Pigtraadene under Bevogtning, og en Gang inde $i$ selve Hovedstaden. Den 23. April oprandt den store Dag, la vi tiltraadte Hjemrejsen. Igennem Ungarn var det en herlig Tur for en Landmand. Markerne var nu gronne og frodige. Ogsaa Køreturen langs med Donaus Bredder var henrivende. Vi gjorde af og til Ophold og fik Mad. Ved Grænsen blev vi undersogt af Lægen, badet og renset paany. Den 30 . April naaede vi Hamborg. Herfra sendte jeg et Telegram hjem og bad om at hente mig med Vogn i Tønder om Aftenen, da Toget ikke gik længere. I Tønder modte jeg saa den forste af mine kære, et Møde, jeg aldrig glemmer. Uen 1. Maj tidlig om Morgenen var jeg i mit kære Hjem. Det var da $1^{1 / 2}$ Aar, siden jeg havde set det. I syv Uger havde jeg Orlov, saa maatte jeg afsted igen, trods min daarlige Haand. Jeg mødte i Graudenz. Kom derfra til Danzig, hror jeg daglig gik paa Lasarettet og fik min Haand behandlet. Derfra blev mange af mine Kammerater 
sendt til Rusland, som en Slags Gendarmer. Jeg skulde ogsaa have varet med, men protesterede og blev fri. Jeg blev saa sentt til Flyverskolen i Stolp i Pommern, hvor jeg gjorde Vagttjeneste. I September fik jeg 14 Dages Orlov paa Grund af sygdom i Hjemmet. To Gange fik jeg til min Overraskelse Orloven forlænget og var saaledes hjemme, da Revolutionen brød uil.

Mine Ben var endinu opsvulmede af Vattersot, da jeg kom hjem; men jeg fik nu Vished on, at det Haab opfylites, der tit havile hjulpet og styrket mig i Krigen; jeg havde hele Tiden stolet paa, at vort Land skulde blive dansk igen. 